\title{
RADIOCARBON FLUCTUATIONS DURING THE THIRD MILLENNIUM BC
}

\section{J C VOGEL, ANNEMARIE FULS, and EBBIE VISSER}

NPRL, CSIR, Pretoria, South Africa

and

\section{BERND BECKER}

Institut für Botanik, Universität Hohenheim, Stuttgart, FRG

ABSTRACT. Precision ${ }^{14} \mathrm{C}$ analyses have been performed on samples comprising 1 to 4 annual rings from the south-central European dendrochronologic sequence of sub-fossil oak wood covering the period 1930 to $3100 \mathrm{BC}$. Apart from a major deviation in the 29 th century $\mathrm{BC}$, the ${ }^{14} \mathrm{C}$ fluctuations have amplitudes of ca $10 \%$ and a possible periodicity of 90 years. $\mathrm{A}^{14} \mathrm{C}$ peak at $2190 \mathrm{BC}$ has a rise- and decay-time of $<20$ years indicating rather abrupt changes in the production rate of ${ }^{14} \mathrm{C}$. The ${ }^{14} \mathrm{C}$ calibration curve derived from these data can be used for precise dating of the Early Bronze Age in the Near East.

The 3rd millennium $\mathrm{BC}$ is that early historic period to which ${ }^{14} \mathrm{C}$ dating can make a positive contribution. It covers, roughly, the time from Dynasty I to the beginning of Dynasty XII in Egypt and the Dynasties of Sumer and Akkad in Mesopotamia, viz, a period during which absolute historic dates are by no means secure. Precision ${ }^{14} \mathrm{C}$ dating, properly applied to archaeologic sites and events in the Near East, could thus be used to refine the historical time scale for this Early Bronze Age period.

With this objective in mind, a high-precision calibration curve for ${ }^{14} \mathrm{C}$ dates is being constructed for the time span 1930 to 3100 BC. From a geophysical point of view, this period (1900-2800 BC) is also of interest because it has been reported as showing no large fluctuations in ${ }^{14} \mathrm{C}$ (Suess, 1980; Pearson, Pilcher \& Baillie, 1983). By analyzing individual annual tree rings from a dendrochronologically-dated sequence, it was hoped to gain more insight into the nature of such a "quiet" period of ${ }^{14} \mathrm{C}$ production.

The samples investigated were annual rings taken from the south-central European sub-fossil oak sequence (Becker, 1979) which has recently been dated absolutely by cross-calibration with a similar Irish oak series (Pilcher et al, 1984). In cases where the rings were narrow, 2 to 4 rings were combined for a sample; otherwise single annual rings were used. The spacing between samples was 10 or 20 years, but several intermediate samples were also measured to define the trends with greater precision. For the purpose of constructing a calibration curve for ${ }^{14} \mathrm{C}$ dates, the use of integrated samples of, say, 20 annual rings may be more appropriate (eg, Pearson \& Baillie, 1983), but since details of short-term variations in ${ }^{14} \mathrm{C}$ would thus be lost, individual rings were preferred.

The samples were reduced to matchstick-size pieces and purified by the de Vries method, viz, they were extracted respectively with $2 \% \mathrm{HCl}, 2 \%$ $\mathrm{NaOH}$, and $2 \% \mathrm{HCl}$ at $70^{\circ} \mathrm{C}$ overnight. The weight loss was normally ca $50 \%$. Tests showed that only ca $1 \%$ by weight could be removed by additional extraction with ethanol/benzene and ethanol in a soxlett. Since it has repeatedly been shown that this organically soluble matter cannot influence the results noticeably (eg, Tans, de Jong \& Mook, 1978), the procedure was not applied to the bulk of the samples.

The purified wood was converted to carbon dioxide which, after puri- fication, was measured in a gas proportional counter for at least two periods of 3 or 4 days. The ${ }^{13} \mathrm{C}$ content of the counter gas was determined before and after counting. The statistical uncertainty of the ${ }^{14} \mathrm{C}$ analyses was in the order of $2 \%$, while the combined error in the determination of gas volume and the uncertainty in the corrections for differences in purity of the gas is estimated to be ca $0.7 \%$. This latter error thus contributes only 1 or 2 years to the inaccuracy of the derived age. At present, the count rate of the NBS oxalic acid standard is known within $\pm 0.5 \%$, while the ratio to the Heidelberg enriched standard, $\mathrm{A}_{\mathrm{Hdb}} / .95 \mathrm{~A}_{\mathrm{ox}}=10.1994 \pm .006$. The ratio between the old and new NBS oxalic acid, both normalized to $\delta^{13} \mathrm{C}=$ $-19 \%$, as measured in this counter is $1.2884 \pm .0009$, which compares well with the average obtained by nine different laboratories, viz, $1.2893 \pm$ .0004 (Mann, 1983).

An error in the estimate of the activity of the NBS oxalic acid as well as an error in the background value can cause a systematic difference between analyses done in different counters and especially in different laboratories. The intercalibration of laboratories remains a problem and systematic differences of 20 to 30 years are probably not unusual.

The results obtained thus far are listed in Table 1. In Figure 1, the conventional ${ }^{14} \mathrm{C}$ age is plotted against the dendrochronologic date of the wood samples. Between 2800 and $2900 \mathrm{BC}$ a relatively large deviation in the ${ }^{14} \mathrm{C}$ content occurs, but for the rest of the millennium (1900-2800 BC) the amplitude of the ${ }^{14} \mathrm{C}$ fluctuations is small. In Figure 2, the deviations from the average trend in ${ }^{14} \mathrm{C}$ are plotted to reveal the nature of these mediumterm variations. Some of the scatter in the curve will be due to the analytical uncertainty of ca $2 \%$ for the individual points, but in those cases where deviations from the mean are substantiated by several measurements, the "wiggles" must be accepted as real. Except for the major fluctuation during the 29th century BC, the amplitudes are ca $10 \%$.

To investigate whether distinct periodicitics occur, the series was subjected to Fourier analysis. The limited number of points and their unequal spacing, however, complicates the analysis and the results are influenced by the specific procedure adopted. Nevertheless, a predominant period of ca 90 years does seem to emerge for our data covering the 3rd millennium BC. This is in contrast with the times during which larger fluctuations occur, eg, in the 2nd millennium AD when amplitudes of $20 \%$ and a period of ca 200 years are obvious (de Vries, 1958; Stuiver, 1982) or during the 1st millennium $\mathrm{AD}$ and the 4th millennium $\mathrm{BC}$ when a periodicity of $150-180$ years has been observed (Bruns, Münnich \& Becker, 1980; de Jong \& Mook, $1980)$. Using his own data Suess (1980) found a predominant period of 202 
years for the whole time span since $6000 \mathrm{BC}$. The recurrence period of 90 years during most of the 3rd millennium $\mathrm{BC}$ seems to suggest that the smaller amplitudes of $10 \%$ are not the result of damping of two nearly similar periodicities in the region of 200 years.

Of special interest is the rapidity with which some of the maxima decay. In Figure 3, the two "wiggles" between 2140 and $2320 \mathrm{BC}$ are shown in detail. The second peak at $2190 \mathrm{BC}$ has both a rise and a decay time of $<20$ years, suggesting that the production rate of ${ }^{14} \mathrm{C}$ must have changed even faster than this. In fact, the decay time is similar to that of the atom bomb ${ }^{14} \mathrm{C}$ in the atmosphere, the production of which was abruptly discontinued in 1962 (Levin et al, 1985). A more gradual change in the natural production rate would inevitably increase the rate at which the ${ }^{14} \mathrm{C}$ concentration decreases. It thus seems that in this instance at least we are observing a rather abrupt event. The question arises as to how common such rapid changes have been and further detailed measurement of other "wiggles" in the sequence would undoubtedly increase our understanding of the nature of their underlying causes. Such measurements need to be undertaken on a year-to-year basis since samples comprising, say, 20 annual rings will obscure the rapid changes that seem to be present.

In order to use the data presented here for the calibration of ${ }^{14} \mathrm{C}$ dates, it must be understood that most samples actually consist of a mixture of biogenic material covering several decades. Different calibration curves constructed from running averages over 20,40 , or 80 years, as the case may be, would thus provide the most accurate conversion date (de Jong, 1981). The optimal use of such curves will, however, require that much more care be taken in the selection of the sample material for dating.

In addition, account needs to be taken of the latitudinal gradient in the ${ }^{14} \mathrm{C}$ content of the atmosphere. The previous finding, that wood samples from $42^{\circ} \mathrm{S}$ Lat contain $(4.5 \pm 1) \% 0$ less ${ }^{14} \mathrm{C}$ than synchronous wood grown at $42^{\circ} \mathrm{N}$ Lat (Lerman, Mook \& Vogel, 1970), has been verified by comparing 6 pairs of annual rings from two trees grown in the Netherlands $\left(53^{\circ} \mathrm{N}\right.$ Lat) and Cape Town $\left(34^{\circ} \mathrm{S}\right.$ Lat), respectively. The results are shown in Table 2. The average difference between the ${ }^{14} \mathrm{C}$ content is $(4.56 \pm .85) \%$, which amply confirms the earlier results. The implication of this is that apparent ${ }^{14} \mathrm{C}$ dates for mid-southern latitudes would all be ca 36 years younger than those for mid-northern latitudes. Since the dendrochronologic series on which calibration curves are based derive from the northern hemisphere, 36 ycars should be subtracted from southern hemisphere dates before conversion to the absolute (historic) time scale.
At present, the measurements are being extended to link up with the series analyzed by de Jong, which covers the years 3200 to $3900 \mathrm{BC}$ (de Jong $\&$ Mook, 1980). Once this has been done, suitable integrated calibration curves spanning the time from the Late Chalcolithic to the beginning of the Middle Bronze Age in the ancient Near East can be constructed. Such curves could then be used for detailed dating of selected archaeologic sites in the region.

\section{ACKNOWLEDGMENTS}

Gertrud von la Chevallerie is thanked for performing, and Siep Talma for supervising the ${ }^{13} \mathrm{C}$ analyses. Wim Mook supplied a section of the Dutch oak listed in Table 2.

\section{REFERENCES}

Becker, B, 1979, Holocene tree-ring series from southern central Europe for archaeology dating radiocarbon calibration, and stable isotope analysis, in Berger, $\mathrm{R}$, and Suess, $\mathrm{H} F$ eds, Radiocarbon dating, Internatl ${ }^{14} \mathrm{C}$ conf, 9th, Proc: Berkeley/Los Angeles, Univ California Press, p 554-565.

Bruns, M, Münnich, K O and Becker, B, 1980, Natural radiocarbon variations from AD 200 to 800 , in Stuiver, M and Kra, R S, eds, Internatl ${ }^{14} \mathrm{C}$ conf, 10 th, Proc: Radiocarbon, v 22 , no. 2 , p $273-277$.

de Jong, A F M, (ms), 1981, Natural ${ }^{14} \mathrm{C}$ variations: PhD dissert, Univ Groningen, The Netherlands.

de Jong, A F M and Mook, W G, 1980, Medium-term atmospheric ${ }^{14} \mathrm{C}$ variations, in Stuiver, $\mathrm{M}$ and Kra, R S, eds, Internatl ${ }^{14} \mathrm{C}$ conf, 10th, Proc: Radiocarbon, v 22, no. 2, p 267-272.

de Vries, H L, 1958, Variations in concentration of radiocarbon with time and location on earth: Koninkl Ned Akad Wet Proc, ser B, v 61, p 94-102.

Lerman, J C, Mook, W G and Vogel, J C, $1970,{ }^{14} \mathrm{C}$ in tree rings from different localities, in Olsson, I U, ed, Radiocarbon variations and absolute chronology, Nobel symposium, 12th: New York, John Wiley \& Sons, p 257-299.

Levin, I, Kromer, B, Schoch-Fischer, H, Bruns, M, Münnich, M, Berdau, D, Vogel, J C and Münnich, K O, 1985, 25 years of tropospheric ${ }^{14} \mathrm{C}$ observations in central Europe: Radiocarbon, v 27, no. 1, p 1-19.

Mann, W B, 1983, An international reference material for radiocarbon dating, in Stuiver, $\mathrm{M}$ and Kra, R S, eds, Internatl ${ }^{14} \mathrm{C}$ conf, 11 th, Proc: Radiocarbon, v 25, no. 2, p 519-527.

Pearson, G W and Baillie, M G, 1983, High-precision ${ }^{14} \mathrm{C}$ measurements of Irish oaks to show the natural atmospheric ${ }^{14} \mathrm{C}$ variations of the $\mathrm{AD}$ time period, in Stuiver, $\mathrm{M}$ and Kra, R S, eds, Internatl ${ }^{14} \mathrm{C}$ conf, 11 th, Proc: Radiocarbon, v 25, no. 2, p 187-196.

Pearson, G W . Pilcher, J R and Baillie, M G, 1983, High-precision ${ }^{14} \mathrm{C}$ measurements of Irish oaks to show the natural ${ }^{14} \mathrm{C}$ variations from $200 \mathrm{BC}$ to $4000 \mathrm{BC}$, in Stuiver, $\mathrm{M}$ and $\mathrm{Kra}$ R S, eds, Internatl ${ }^{14} \mathrm{C}$ conf, 11 th, Proc: Radiocarbon, v 25, no. 2, p 179-188.

Pilcher, J R, Baillie, M G, Schmidt, B and Becker, B, 1984, A 7,272-year tree-ring chronology for western Europe: Nature, v 312, p 150-152.

Stuiver, M, 1982, A high-precision calibration of the AD radiocarbon time scale: Radiocarbon, v 24 , no. $1, \mathrm{p} 1-26$.

Suess, H E, 1980, The radiocarbon record in tree rings of the last 8000 years, in Stuiver, M and Kra, R S, eds, Internatl ${ }^{14} \mathrm{C}$ conf, 10 th, Proc: Radiocarbon, v 22, no. 2, p 200-209.

Tans, P P, de Jong, A F M and Mook, W G, 1978, Chemical pretreatment and radial flow of ${ }^{14} \mathrm{C}$ in tree rings: Nature, v 271, p 234-235. 


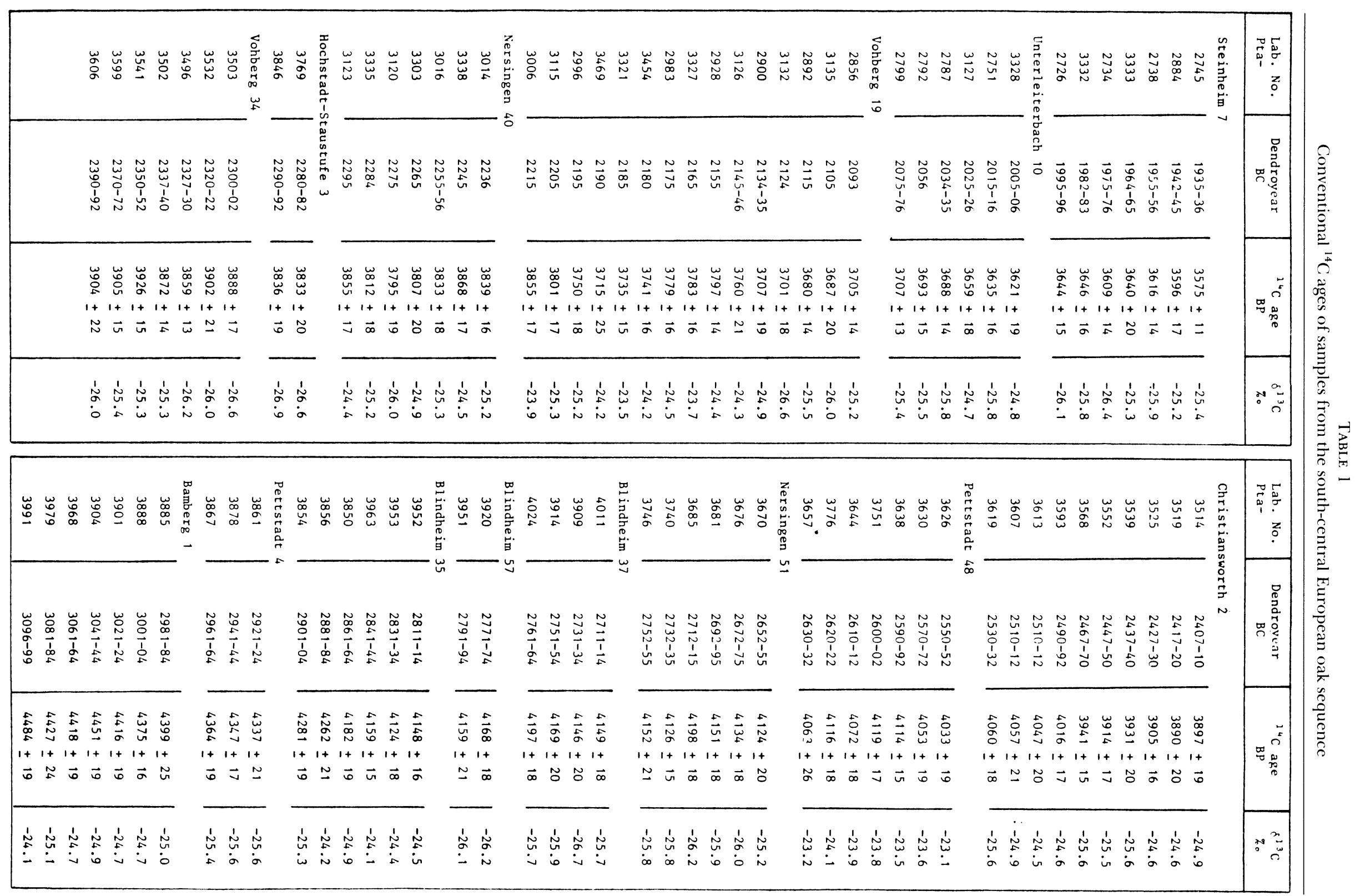


TABLE 2

Difference between ${ }^{14} \mathrm{C}$ contents of annual rings from an oak grown in northern Netherlands $\left(53^{\circ} \mathrm{N}\right.$ Lat) and a pine grown in Cape Town $\left(34^{\circ} \mathrm{S}\right.$ Lat $)$.

\begin{tabular}{|c|c|c|c|}
\hline $\begin{array}{c}\text { Dendroyear } \\
\mathrm{AD}\end{array}$ & $\begin{array}{c}\text { Dutch Oak } \\
\Delta^{14} \mathrm{C} \\
\% \circ\end{array}$ & $\begin{array}{c}\text { Cape Town Pine } \\
\Delta^{14} \mathrm{C} \\
\% \circ\end{array}$ & $\begin{array}{c}\text { Difference } \\
\% \circ\end{array}$ \\
\hline 1840 & $-5.0 \pm 1.7$ & $-8.6 \pm 1.9$ & $3.6 \pm 2.6$ \\
1850 & $-4.2 \pm 1.7$ & $-6.2 \pm 1.4$ & $2.0 \pm 2.0$ \\
1860 & $-4.8 \pm 1.7$ & $-8.9 \pm 1.6$ & $4.1 \pm 2.3$ \\
1870 & $-2.8 \pm 1.5$ & $-12.3 \pm 1.4$ & $9.4 \pm 2.1$ \\
$1879-80$ & $-5.5 \pm 1.6$ & $-9.9 \pm 0.9$ & $4.4 \pm 1.8$ \\
1890 & $-7.6 \pm 1.6$ & $-11.4 \pm 1.1$ & $3.9 \pm 1.9$ \\
\cline { 3 - 5 } & \multicolumn{2}{|c}{ Ave } & $4.56 \pm 0.85$ \\
\cline { 3 - 4 } & & &
\end{tabular}

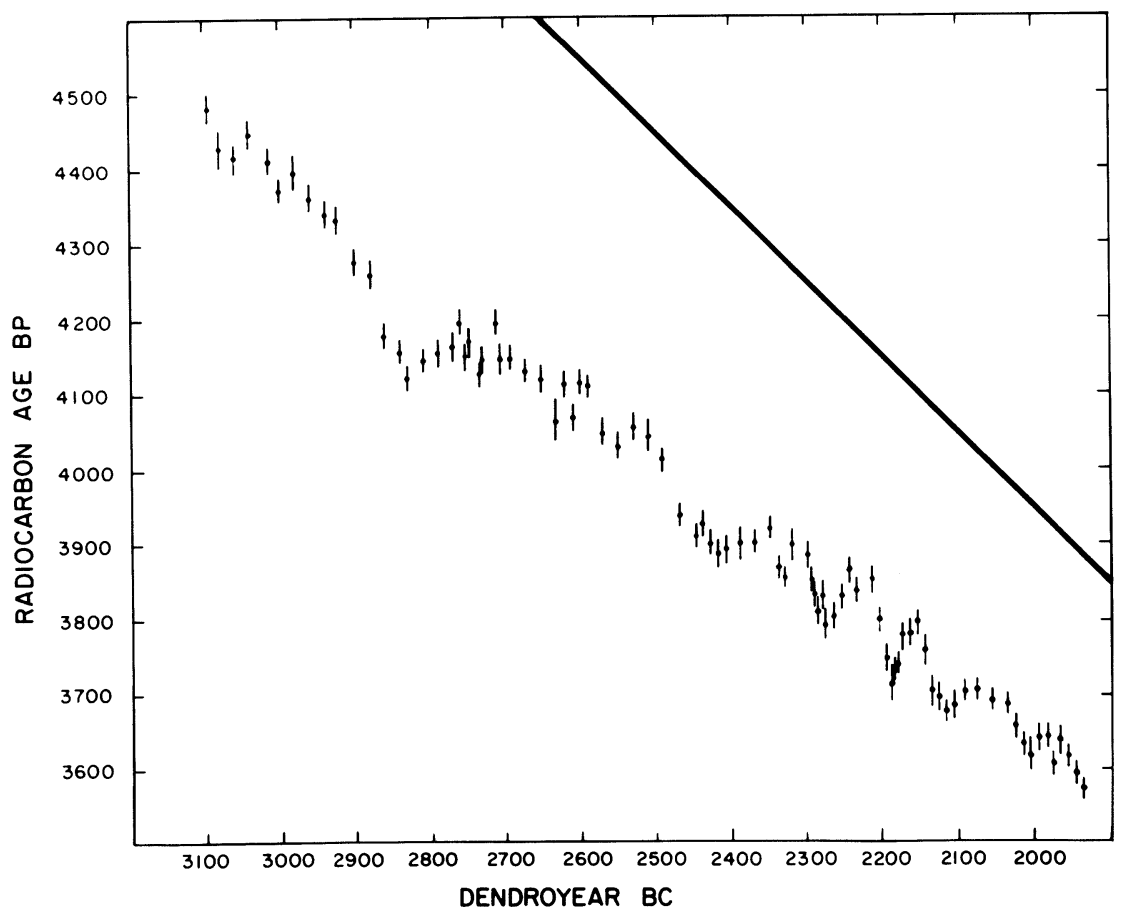

Fig 1. Conventional ${ }^{14} \mathrm{C}$ age plotted against the dendro-age of oak wood from southern Germany $\left(48^{\circ} \mathrm{N}\right.$ Lat $)$

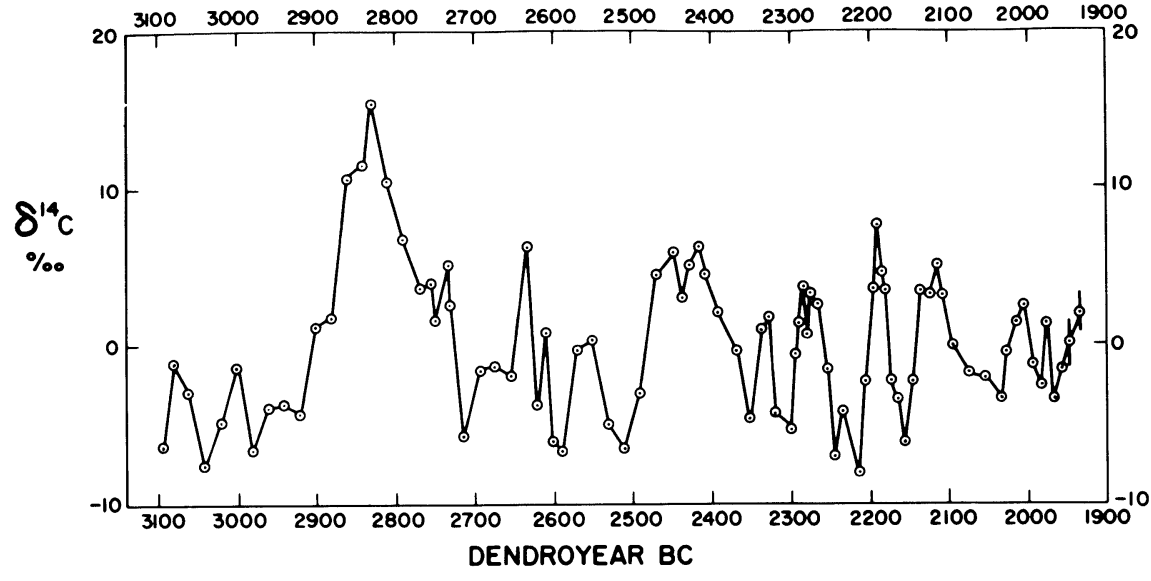

Fig 2. Deviations from the mean trend in the ${ }^{14} \mathrm{C}$ content between 1930 and $3100 \mathrm{BC}$

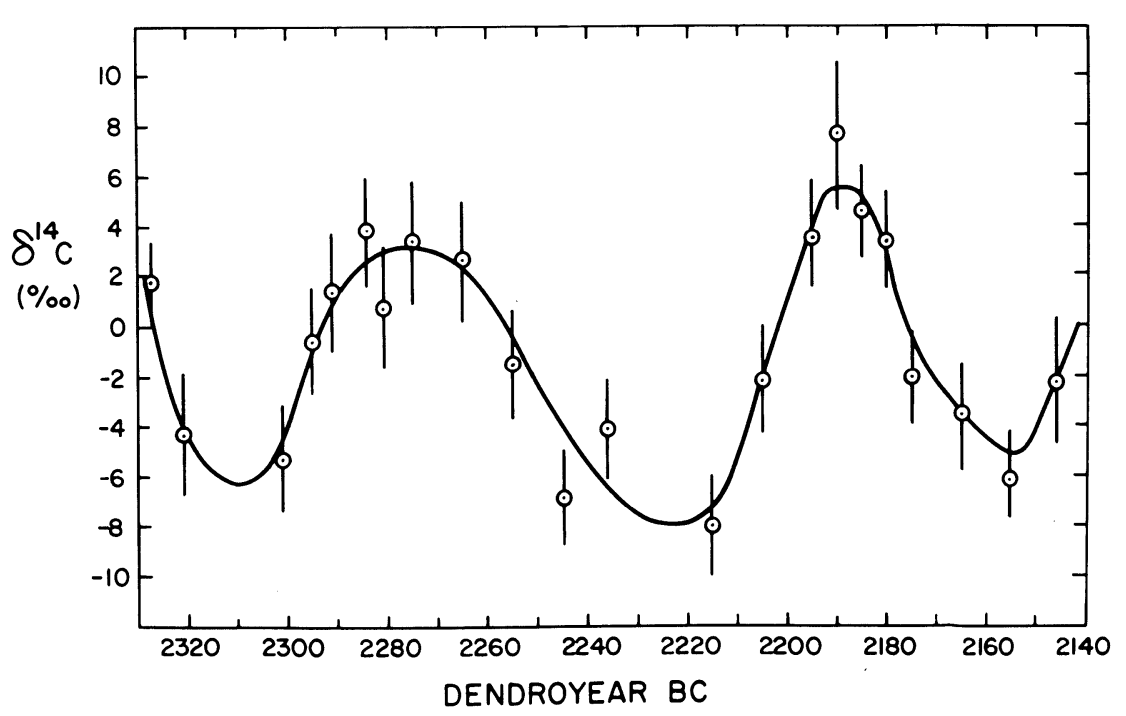

Fig 3. Fluctuations in the ${ }^{14} \mathrm{C}$ content between 2140 and $2320 \mathrm{BC}$ 